\title{
TJBF RISK-ADJUSTED RETURNS OF AMERICAN DEPOSITARY RECEIPTS ON CHINESE AND INDIAN STOCKS
}

\author{
Onur Arugaslan and Ajay Samant \\ Western Michigan University
}

\begin{abstract}
This study evaluates the risk-adjusted performance of American Depositary Receipts (ADRs) on shares of stock of Chinese and Indian firms. The first part of the study examines the nature of Chinese and Indian ADRs (based on depositary bank, sponsorship status, industry classification and listing). The second part of the study evaluates the performance of these ADRs using statistical measures grounded in modern portfolio theory. Returns are adjusted for the degree of total risk and systematic risk inherent in each ADR, and the securities are then ranked on the basis of risk-adjusted performance. Two relatively new evaluation metrics, the Modigliani and Sortino measures, are used. The objective of the study is to provide documentation to global investors who are contemplating participation in Chinese and Indian stock markets via depositary receipts.
\end{abstract}

Keywords: ADRs, Portfolio choice, Investment decisions, Emerging markets JEL Classifications: G15, G11, F30

\section{Introduction}

There has been a significant rise in investor comfort over the past decade with global financial securities, aided by the ease and convenience with which transnational corporate information can be accessed via the internet and other means. One of the most convenient vehicles for accessing corporate securities listed outside the investor's home country is a Global Depositary Receipt. In the United States, these securities are known as American Depositary Receipts (ADRs). As of August 2007, there were 1,703 ADRs listed on the New York Stock Exchange (NYSE), American Stock Exchange (AMEX), the NASDAQ system, and on private trading networks.

This study examines the nature and performance of ADRs on shares of firms incorporated in China and India. As is well known, China and India are the two largest countries in the world in terms of population, and each country has a 
diversified industrial base, a rapidly growing consumer market, and an emerging stock market. Table 1 summarizes information such as market capitalization, gross domestic product, and labor force for these two countries. As a result of excellent growth opportunities evident in those numbers, each of these countries is under increasing scrutiny by international investors.

Table 1: Summary Economic Measures for China and India

\begin{tabular}{lrr}
\hline & \multicolumn{1}{c}{ China } & \multicolumn{1}{c}{ India } \\
\hline Market Capitalization (\$ million)* $^{*}$ & 780,763 & 553,074 \\
Value Traded (\$ million)* & 586,301 & 443,175 \\
Number of Listed Domestic Companies* & 1,387 & 4,763 \\
Average Company Size (\$ million)* & 562.9 & 116.1 \\
Gross Domestic Product (GDP) (\$ billion)** & 2,518 & 804 \\
GDP Growth (2005-2006) & $10.7 \%$ & $9.2 \%$ \\
Average GDP Growth (1990-2006) & $9.8 \%$ & $6.1 \%$ \\
Labor Force (million)** & 798 & 509.3 \\
$*$ 2005, **2006 & & \\
\hline
\end{tabular}

Many of these investors find it inconvenient, for a variety of reasons, to invest directly in stock markets in China and India, and, therefore, prefer to invest in ADRs based on Chinese and Indian stocks. These ADRs may be created at the request of investors or corporations whose stock is held in trust as collateral for the ADR. These securities serve a dual purpose: they enable firms incorporated in China and India to raise funds in developed capital markets without having to meet the stringent listing requirements of U.S. and European stock exchanges, and, at the same time, enable global investors to earn returns on securities listed on emerging markets without the dual inconvenience of having to deal with time difference between countries and with currency conversion.

This study examines the nature of Chinese and Indian ADRs, sorted on basis of depositary bank, sponsorship status, industry classification, and stock exchange on which the security is listed. Data are obtained from the Bank of New York and CRSP. The intent of the study is to provide documentation to international investors who would like to hold ADRs from China and India in their global portfolios. The study should be of interest to international investors, managers of mutual funds who are exploring opportunities to diversify their global portfolios, managers of corporations who are planning to sponsor the issue of depositary receipts, and to bank managers who provide international financial services.

The primary securities that underlie an ADR may be corporate stocks or bonds. The earliest ADRs (1927) were issued at the request of institutional investors. These ADR are "unsponsored." Most of the ADRs that are currently listed are "sponsored" programs, issued at the request of the firm whose securities underlie the ADR. When a sponsored ADR is issued, there may or may not be 
a corresponding creation of new capital. There are four grades of sponsored ADRs. Level I ADRs are trade in the OTC market. Level II ADRs trade on national stock exchanges (such as the NYSE). If new capital is raised during the process of issuing sponsored ADRs, then the ADRs are categorized as Level III and IV. Level III ADRs are listed on national stock exchanges. Level IV ADRs are privately listed, and are usually issued under rule 144A of the US Securities and Exchanges Commission.

This study examines the nature and performance of ADRs on Chinese and Indian firms. The rest of the paper is structured as follows. Section 2 reviews the literature on ADRs and summarizes pertinent studies in the area of modern portfolio theory. Section 3 examines the sponsorship status, choice of depositary bank, industrial classification, and market listing. Section 4 evaluates the performance of these ADRs on a risk-adjusted basis, using the Morgan Stanley Capital International (MSCI) Europe, Australasia, and Far East (EAFE) Index as a benchmark for comparison purposes. Section 5 concludes the paper.

\section{Literature Review}

Treynor (1965), Sharpe (1966), and Jensen (1968) pioneered the evaluation of the performance of investment portfolios. They developed statistical techniques that are the most commonly used portfolio performance measures even today. Treynor (1965) suggested a way of evaluating the performance of a portfolio by adjusting the mean excess return for the degree of market risk and thus calculating the performance of the portfolio. Sharpe (1966) computed mean excess return and adjusted for the degree of total risk involved in the portfolio. Jensen (1968) devised a method of determining whether the deviation of portfolio returns from market returns was statistically significant, and, therefore, determining whether the excess return could be attributed to superior management, or purely to chance. The techniques used in these three pioneering studies were further refined by Kon and Jen (1979), Henrikkson and Merton (1981), and Chang and Lewellen (1984).

Later on, Modigliani and Modigliani (1997) did some pioneering work in the area of financial reward and risk. They proposed a new risk-adjusted performance measure (hereafter referred to as, M Squared), which is intuitively quite appealing to investors. The idea that underlies their methodology is to adjust the returns of a portfolio to the level of risk in an unmanaged stock market index and then measure the returns on the risk-matched portfolio. Separately, academicians and practitioners in finance have shown an interest in downside risk measures for evaluating portfolio performance. The most widely cited performance measure that adjusts for downside risk is the Sortino Ratio (Sortino and Price, 1994). In this paper, we use a modified Sortino Ratio that was introduced by Pedersen and Satchell (2002), who show that this ratio has a sound theoretical foundation.

Academics have studied the benefits of global diversification of investment portfolios extensively. Solnik (1996) presents an excellent summary of these 
benefits. Officer and Hoffmeister (1987) show that portfolio risk can be reduced significantly by including ADRs in a portfolio of purely domestic (U.S.) securities. Aggarwal, Dahiya, and Klapper (2005) analyze the investment allocation decision of mutual fund managers to invest in emerging market firms that are listed in their domestic markets and have issued ADRs in the U.S. as well. They find that ADRs are the preferred mode of holdings if the local market of the issuer has weak investor protection, low liquidity and high transaction costs, and if the firm is small and has limited analyst following. The motivation for cross-listing shares on foreign exchanges has also been widely researched (Saudagaran, 1988). Umutlu, Salih, and Akdeniz (2007) investigate the consequences of cross listing and find that ADR listing does not have any effect on the volatility of the underlying stock. On the other hand, Jaiswal-Dale and Jithendranathan (2001) report that the ADRs capture the fluctuations of both the domestic and U.S. markets.

The relation between the price of ADRs and the underlying shares has also been studied thoroughly (Alexander, Eun, and Janakiramanan, 1987; Alexander, Eun, and Janakiramanan, 1988). Jayaraman, Shastri, and Tandon (1993) study the impact of international cross-listings using ADRs. Because ADRs can be exchanged for the underlying shares, financial arbitrage usually ensures that the price of an ADR is within transactions costs of the price of the underlying share. Interestingly, in a recent study Eichler and Maltritz (2008) develop an options-based approach to model the probability of a currency crisis as a function of the deviation of the ADR price from the price of the underlying stock.

To the knowledge of the authors, this is the first study of the nature and performance of ADRs on Chinese and Indian firms, particularly, their sponsorship status, industrial classification, names of banks that are active in this business, and exchanges on which these ADRs are listed. This is also the first rigorous study of the returns that have accrued to these ADRs, from the point of view of US based investors. The results of this study should be of interest to investors and mutual fund managers who are looking for opportunities to diversify their international portfolios, to managers of Chinese and Indian firms who are contemplating sponsoring the issue of these securities in US markets, and to the managers of banks, which provide international financial services.

\section{Nature of ADRs from China and India}

As of November 2006, there were 73 ADR issues on Chinese firms and 88 ADR issues on Indian firms, listed on U.S. capital markets. All ADRs from China and India were sponsored. Regarding the financial institutions that have issued the Chinese ADRs, the Bank of New York accounted for 50 of these issues, followed by Citibank with 11, J.P. Morgan Chase with 10 issues, and Deutsche Bank with two issues. Thirty-six ADRs from India were issued by the Bank of New York, 25 by Citibank, 21 by Deutsche Bank, and six by J.P. Morgan Chase. 
Regarding the exchanges on which these securities are listed, of the 73 Chinese ADRs, 20 were listed on NASDAQ, 18 were listed on the NYSE, 27 were listed on OTC (other than NASDAQ), and 8 were listed on Portal. Ten ADRs from India were listed on the NYSE, three were listed on NASDAQ, 73 were listed on Portal, and the other two were OTC.

Regarding industrial classification, 8 of the Chinese ADRs were in the software and computer services industry; 7 in travel and leisure; 5 each in mobile telecommunications and technological hardware and equipment; 4 each in industrial engineering, industrial transportation, and real estate; 3 each in chemicals, electricity, life insurance, industrial metals, and oil and gas producers; 2 each in automobiles and parts, food producers, health care equipment and services, leisure goods, mining, and pharmaceuticals and biotechnology; 1 each in beverages, construction and materials, electronics and electric equipment, fixed line telecommunications, gas, water, and multiutility, general retailers, media, oil equipment, services, and distribution, and support services.

With respect to industrial classification, 12 of the Indian ADRs were in the software and computer services industry; 9 in chemicals, 7 each in banking and construction and materials; 6 in personal goods; 5 in industrial engineering; 4 each in fixed line telecommunications, food producers, general finance, and pharmaceuticals and biotechnology; 3 each in electricity, electronics and electric equipment, industrial metals, and technological hardware and equipment; 2 each in industrial transportation and travel and leisure; 1 each in automobiles and parts, beverages, food and drug retailers, forestry and paper, gas, water, and multiutility, general industrials, health care equipment and services, household goods, oil equipment, services, and distribution, and support services. All data are obtained from the website of the Bank of New York.

\section{Performance of ADRs from China and India}

\section{A. Data and Methodology}

Monthly return data for the three-year period January 2003 - December 2005 are obtained from CRSP. Bank of New York ADR Index includes 35 ADRs from China and 12 ADRs from India. CRSP has full return data for 14 Chinese ADRs and 9 Indian ADRs. Therefore, the final sample for the performance analysis consists of 23 ADRs. The return on U.S. 4-week Treasury Bills is used as the proxy for the risk-free rate. The MSCI EAFE Index is utilized as the market benchmark.

Monthly returns are averaged over the three-year period to obtain the Mean return. Risk-free rate of return is subtracted from the mean return to compute the Mean excess return. Mean excess return of each ADR is divided by its standard deviation to compute the Sharpe measure:

$$
S_{i}=\frac{R i-R f}{\sigma i}
$$


where $\mathrm{R}_{\mathrm{i}}=$ mean return on ADR $\mathrm{i}$,

$\mathrm{R}_{\mathrm{f}}=$ mean risk-free rate of return, and

$\mathrm{s}_{\mathrm{i}}=$ standard deviation of returns for ADR $\mathrm{i}$.

Mean excess return of each ADR is divided by its beta to obtain the Treynor measure:

$$
T_{i}=\frac{R i-R f}{\beta_{i}}
$$

where $b_{i}$ is estimated from the market model:

$$
\begin{array}{cc}
R_{i t}= & \alpha_{i}+\beta_{i} R_{m t}+e_{i t} \\
\text { where } & \mathrm{R}_{\mathrm{mt}}=\text { market return during period } \mathrm{t}, \text { and } \\
& \mathrm{e}_{\mathrm{it}}=\text { error term. }
\end{array}
$$

Expected return of each ADR is subtracted from its actual mean return to compute Jensen's Alpha:

$$
\alpha_{i}=R i-E\left[R_{i}\right]
$$

where the expected return for each ADR is obtained using the Capital Asset Pricing Model:

$$
E\left[R_{i}\right]=R_{f}+\beta_{i}(R m-R f)
$$

Jensen's Alphas are then tested for statistical significance.

Mean excess return for each ADR is divided by the downside deviation of that ADR's return from the risk-free rate of return to compute The Sortino Ratio:

$$
S O i=\frac{R i-R f}{D D_{i}}
$$

where the downside deviation is estimated as follows:

$$
\mathrm{DDi}=\left[\frac{1}{n-1} \sum_{j=1}^{n}\left(\max \left\{0, R_{f}-R_{i j}\right\}\right)^{2}\right]^{1 / 2}
$$

Sharpe measure is multiplied by the market standard deviation and then the risk-free rate added to calculate the $M$ Squared measure:

$$
M_{i}^{2}=\frac{R i-R f}{\sigma i} \sigma m+R f
$$


Finally, the benchmark standard deviation is divided by the ADR standard deviation to obtain the Leverage Factor:

$$
L_{i}=\frac{\sigma m}{\sigma i}
$$

Leverage Factor reports a comparison of the total risk in the ADR with the total risk in the market portfolio. For example, a Leverage Factor less than one implies that the risk of the ADR is greater than the risk of the market index, and that the investor should consider unlevering the ADR by selling off part of the holding in the ADR and investing the proceeds in a risk-free security, such as a Treasury bill. On the other hand, a Leverage Factor greater than one implies that the standard deviation of the ADR is less than the standard deviation of the market index, and that the investor should consider levering the ADR by borrowing money (if possible, at the risk-free rate of return) and investing in that particular ADR.

\section{B. Results}

The 23 ADRs with full monthly return data are identified in Table 2 along with their risk, return, and performance statistics. Returns, of course, are reported in US dollars. The ADRs are ranked in alphabetical order for each country and Chinese ADRs are listed first, followed by Indian ADRs. The ADR with the highest mean return is Rediff.com India with an average monthly return of 10.63 percent. Aluminum Corporation of China leads the Chinese ADRs with an average monthly return of 6.23 percent. In comparison, the monthly mean return of the benchmark MSCI EAFE Index is 1.83 percent. The ADR with the highest total risk (measured by the standard deviation of returns) is again Rediff.com India with a monthly standard deviation of 25.59 percent. The Chinese ADR with the highest monthly standard deviation (18.74 percent) is Netease.com. In comparison, the standard deviation of the benchmark MSCI EAFE Index is 3.51 percent.

Further, Table 2 reports the numerical values of the Sharpe and Sortino measures, which are used to rank the ADRs in Table 3. The highest Sharpe and Sortino measures obtained (0.48 and 1.14) are by HDFC Bank from India. The highest Sharpe measure (0.42) for the Chinese ADRs is by CNOOC (China National Offshore Oil Company) and the highest Sortino measure (1.12) is by PetroChina. In comparison, the Sharpe measure and the Sortino measure of the benchmark MSCI EAFE Index is 0.48 and 1.05 , respectively.

Table 2 also reports the values of ADR Betas, M Squared measures, Jensen's Alphas (and their t-statistics), and Treynor measures, all of which are computed using the benchmark MSCI EAFE Index. The ADR with the highest systematic risk $(B e t a=2.14)$ is Aluminum Corporation of China. The Indian ADR with the highest Beta (1.89) is Videsh Sanchar Nigam. In comparison, the Beta of the benchmark MSCI EAFE Index is, by definition, exactly 1.0. The ADR with the highest M Squared measure (1.83) is HDFC Bank from India. Among the Chinese ADRs, the highest M Squared measure (1.62) is by CNOOC. In comparison, the benchmark MSCI EAFE index has an M Squared measure of 


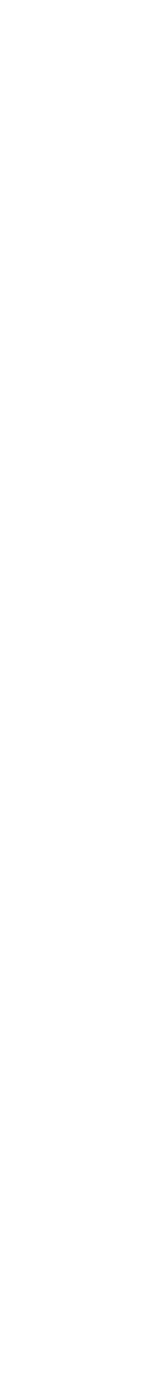

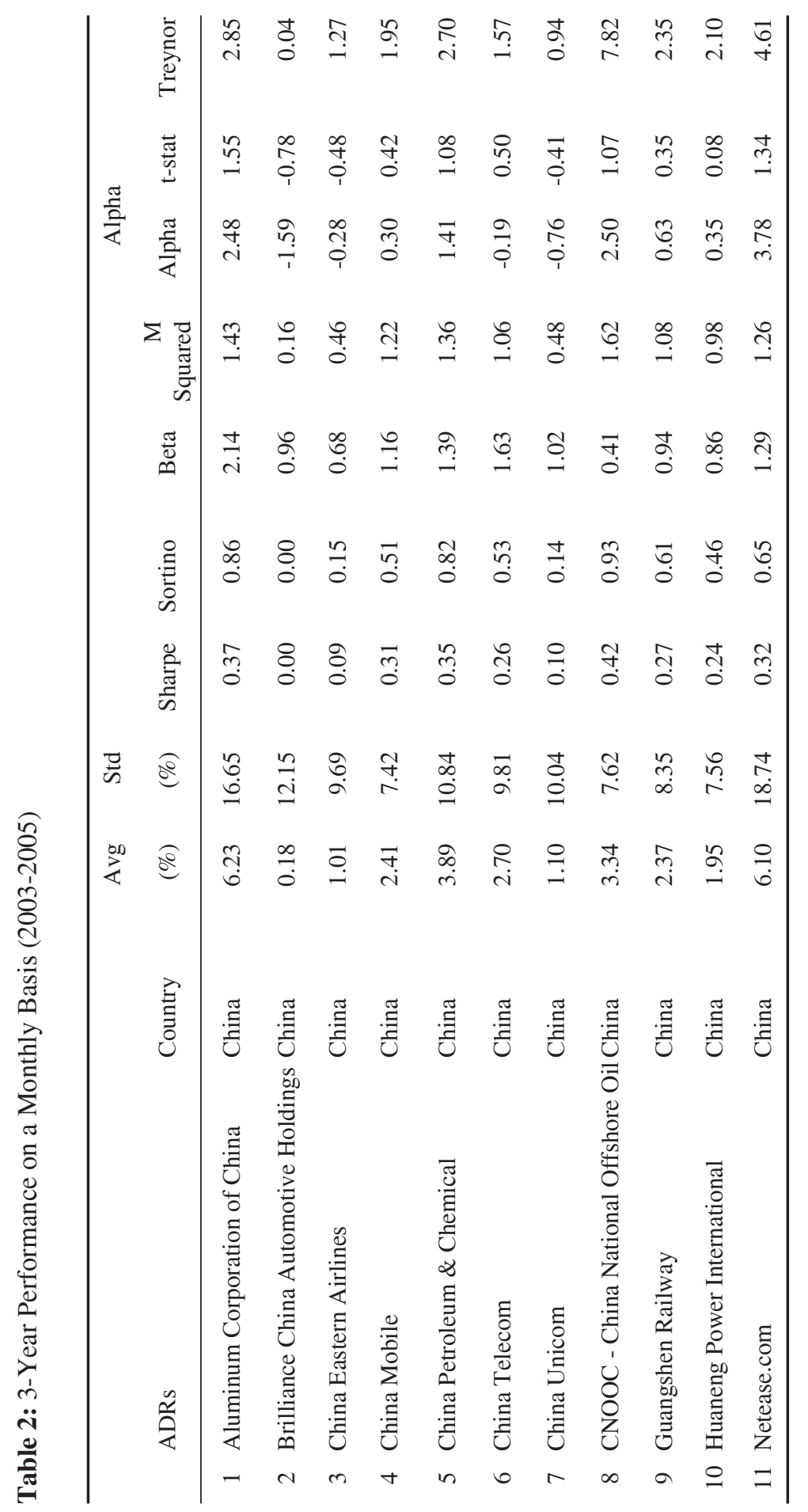




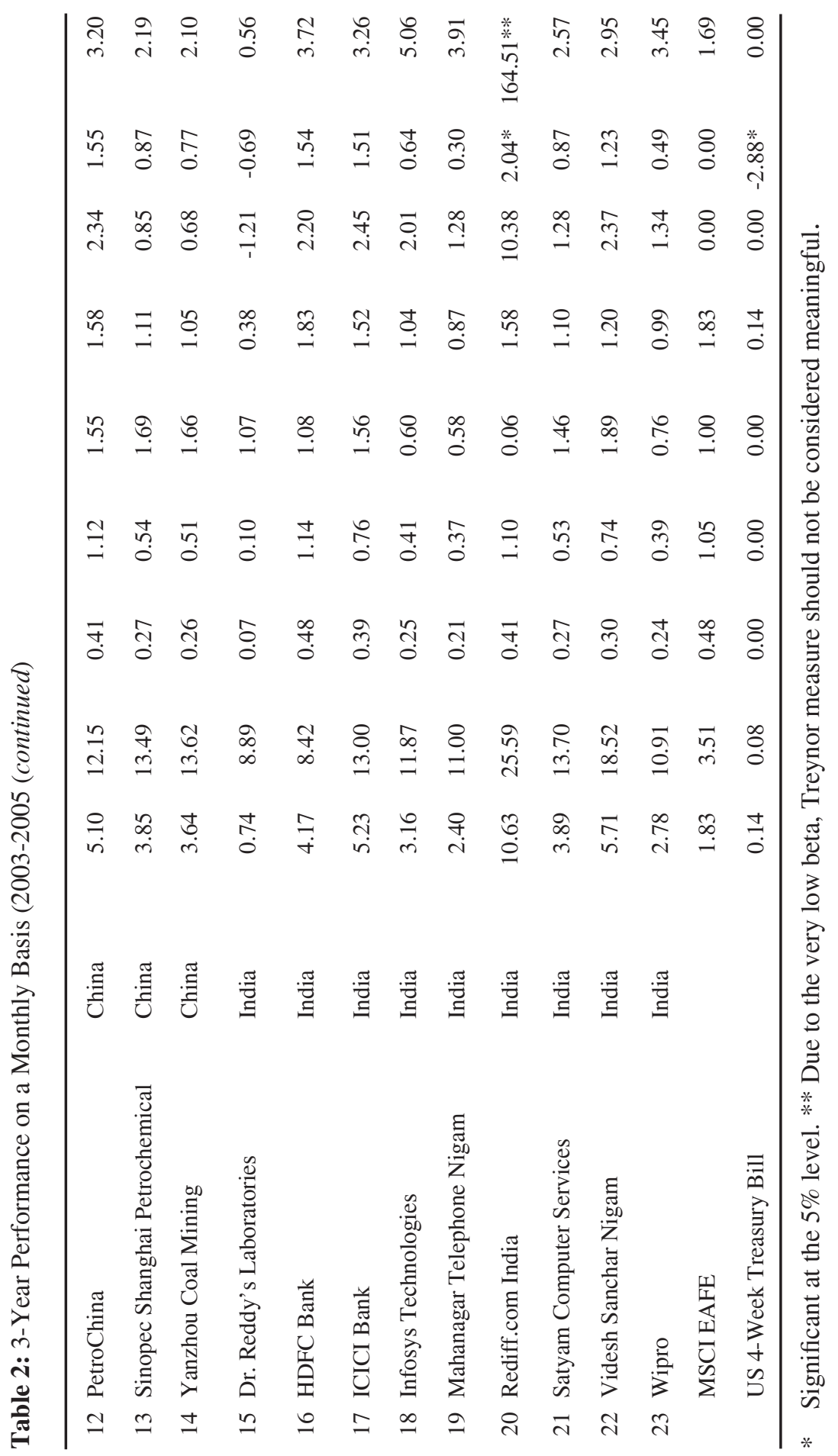


1.83. The ADR with the highest Alpha measure is Rediff.com India with Alpha equal to 10.38 , which is significant at the five percent level.

The Chinese ADR with the highest Alpha (3.78) is Netease.com, but this Alpha is not significant. The Alpha measure of the benchmark MSCI EAFE Index is, by definition, zero. None of the other ADR Alphas is significantly different from zero. Finally, the ADR with the highest Treynor measure (164.51) is Rediff.com India. CNOOC is the leading Chinese ADR with a Treynor measure of 7.82. In comparison, the Treynor measure for the MSCI EAFE Index is 1.69 ).

Table 3: 3-Year Ranking (2003-2005)

\begin{tabular}{|c|c|c|c|c|c|}
\hline $\begin{array}{c}\text { ADRs } \\
\text { Panel A: } \text { Whole Sample }\end{array}$ & Country & $\begin{array}{c}\text { Sharpe Rank } \\
\text { (M Squared } \\
\text { Rank) }\end{array}$ & $\begin{array}{c}\text { Sortino } \\
\text { Rank }\end{array}$ & $\begin{array}{c}\text { Treynor } \\
\text { Rank }\end{array}$ & $\begin{array}{l}\text { Alpha } \\
\text { Rank }\end{array}$ \\
\hline MSCI EAFE & & 1 & 4 & 19 & 19 \\
\hline HDFC Bank & India & 2 & 1 & 6 & 8 \\
\hline $\begin{array}{l}\text { CNOOC - China National Off- } \\
\text { shore Oil }\end{array}$ & China & 3 & 5 & 2 & 3 \\
\hline Rediff.com India & India & 4 & 3 & 1 & 1 \\
\hline PetroChina & China & 5 & 2 & 9 & 7 \\
\hline ICICI Bank & India & 6 & 8 & 8 & 5 \\
\hline Aluminum Corporation of China & China & 7 & 6 & 11 & 4 \\
\hline China Petroleum \& Chemical & China & 8 & 7 & 12 & 10 \\
\hline Netease.com & China & 9 & 10 & 4 & 2 \\
\hline China Mobile & China & 10 & 16 & 18 & 18 \\
\hline Videsh Sanchar Nigam & India & 11 & 9 & 10 & 6 \\
\hline Sinopec Shanghai Petrochemical & China & 12 & 12 & 15 & 14 \\
\hline Satyam Computer Services & India & 13 & 13 & 13 & 13 \\
\hline Guangshen Railway & China & 14 & 11 & 14 & 16 \\
\hline China Telecom & China & 15 & 14 & 20 & 20 \\
\hline Yanzhou Coal Mining & China & 16 & 15 & 16 & 15 \\
\hline Infosys Technologies & India & 17 & 18 & 3 & 9 \\
\hline Wipro & India & 18 & 19 & 7 & 11 \\
\hline Huaneng Power International & China & 19 & 17 & 17 & 17 \\
\hline Mahanagar Telephone Nigam & India & 20 & 20 & 5 & 12 \\
\hline
\end{tabular}


Table 3: 3-Year Ranking (2003-2005)

\begin{tabular}{|c|c|c|c|c|c|}
\hline China Unicom & China & 21 & 22 & 22 & 22 \\
\hline China Eastern Airlines & China & 22 & 21 & 21 & 21 \\
\hline Dr. Reddy's Laboratories & India & 23 & 23 & 23 & 23 \\
\hline $\begin{array}{l}\text { Brilliance China Automotive } \\
\text { Holdings }\end{array}$ & China & 24 & 24 & 24 & 24 \\
\hline \multicolumn{6}{|l|}{ Panel B: Chinese Sub-Sample } \\
\hline MSCI EAFE & & 1 & 2 & 11 & 11 \\
\hline $\begin{array}{l}\text { CNOOC - China National Off- } \\
\text { shore Oil }\end{array}$ & & 2 & 3 & 1 & 2 \\
\hline PetroChina & & 3 & 1 & 3 & 4 \\
\hline Aluminum Corporation of Chin & & 4 & 4 & 4 & 3 \\
\hline China Petroleum \& Chemical & & 5 & 5 & 5 & 5 \\
\hline Netease.com & & 6 & 6 & 2 & 1 \\
\hline China Mobile & & 7 & 11 & 10 & 10 \\
\hline Sinopec Shanghai Petrochemica & & 8 & 8 & 7 & 6 \\
\hline Guangshen Railway & & 9 & 7 & 6 & 8 \\
\hline China Telecom & & 10 & 9 & 12 & 12 \\
\hline Yanzhou Coal Mining & & 11 & 10 & 8 & 7 \\
\hline Huaneng Power International & & 12 & 12 & 9 & 9 \\
\hline China Unicom & & 13 & 14 & 14 & 14 \\
\hline China Eastern Airlines & & 14 & 13 & 13 & 13 \\
\hline $\begin{array}{l}\text { Brilliance China Automotive } \\
\text { Holdings }\end{array}$ & & 15 & 15 & 15 & 15 \\
\hline \multicolumn{6}{|l|}{ Panel C: Indian Sub-Sample } \\
\hline MSCI EAFE & & 1 & 3 & 9 & 9 \\
\hline HDFC Bank & & 2 & 1 & 4 & 4 \\
\hline Rediff.com India & & 3 & 2 & 1 & 1 \\
\hline ICICI Bank & & 4 & 4 & 6 & 2 \\
\hline Videsh Sanchar Nigam & & 5 & 5 & 7 & 3 \\
\hline Satyam Computer Services & & 6 & 6 & 8 & 8 \\
\hline Infosys Technologies & & 7 & 7 & 2 & 5 \\
\hline Wipro & & 8 & 8 & 5 & 6 \\
\hline Mahanagar Telephone Nigam & & 9 & 9 & 3 & 7 \\
\hline Dr. Reddy's Laboratories & & 10 & 10 & 10 & 10 \\
\hline
\end{tabular}


Table 3 Panel A reports the rankings of all the ADRs. The Treynor and Alpha ranks in Table 3 indicate that, 18 ADRs have returns (adjusted for systematic risk) that, exceed the risk-adjusted returns of the MSCI EAFE Index. The Sharpe ranks indicate that none of the ADRs has returns (adjusted for total risk) that exceed the risk-adjusted returns of the MSCI EAFE Index. The Sortino ranks indicate that only HDFC Bank (India), PetroChina, and Rediff.com India have returns (adjusted for downside risk) that exceed the risk-adjusted returns of the MSCI EAFE Index. The ranking based on the M Squared measure is identical to the ranking based on the Sharpe measure. However, the M Squared measure enables us to draw some inferences, which cannot be drawn from the Sharpe measure (or, as a matter of fact, from any other measure), and these are detailed at the end of this section. Panel B and Panel C show the rankings for the Chinese and Indian sub-samples, respectively.

Table 4 Panel A reports the average returns that accrue to the whole sample of ADRs with and without risk-adjustment. The risk-adjustment is performed by using the MSCI EAFE Index as the benchmark. The returns are annualized for the convenience of investors. This is done by compounding the monthly mean returns over twelve periods. In that panel, Rediff.com India, which ranks first based on unadjusted returns, falls back to rank four on the basis of returns adjusted for risk. Aluminum Corporation of China ranks second on the basis of unadjusted returns, but falls back to rank seven based on returns adjusted for risk. Netease.com, which ranks third on the basis of unadjusted returns, falls back to rank nine on the basis of returns adjusted for risk. On the other hand, MSCI EAFE, which ranks 20th on an unadjusted basis, ranks first when the returns are adjusted for risk. HDFC Bank (India), which ranks seventh on an unadjusted basis, ranks second when the returns are adjusted for risk. CNOOC, which ranks 12th on an unadjusted basis, ranks third when the returns are adjusted for risk. The leverage factor for this ADR is 0.46, which implies that an investor, who is comfortable with bearing the same level of risk as in the benchmark MSCI EAFE index, could unlever the ADR (lend 54 percent of her down payment, if possible, at the risk-free rate of interest and invest the rest in the ADR) and thereby attain an annual return level of 21.22 percent. The example below details how this return can be obtained.

Consider an investor who would like to earn superior returns on an ADR and, at the same time, bear only an average level of risk. In this context, the average level of risk is measured by the standard deviation of the benchmark MSCI EAFE index, which is 3.51 percent on a monthly basis. Now consider the following investment strategy: Suppose that the investor has $\$ 1,000$ to invest. The investor could lend $\$ 540$ and invest $\$ 460$ in CNOOC. The end of month return from the ADR portion of the portfolio will be $\$ 460$ x $0.0334=\$ 15.36$. Suppose that the loaned funds were given at the monthly risk-free rate of 0.14 percent. In that case, the loaned funds will bring $\$ 540 \times 0.0014=\$ 0.76$. The portfolio return is $\$ 15.36+0.76=\$ 16.12$, which is a return of 1.61 percent on a 


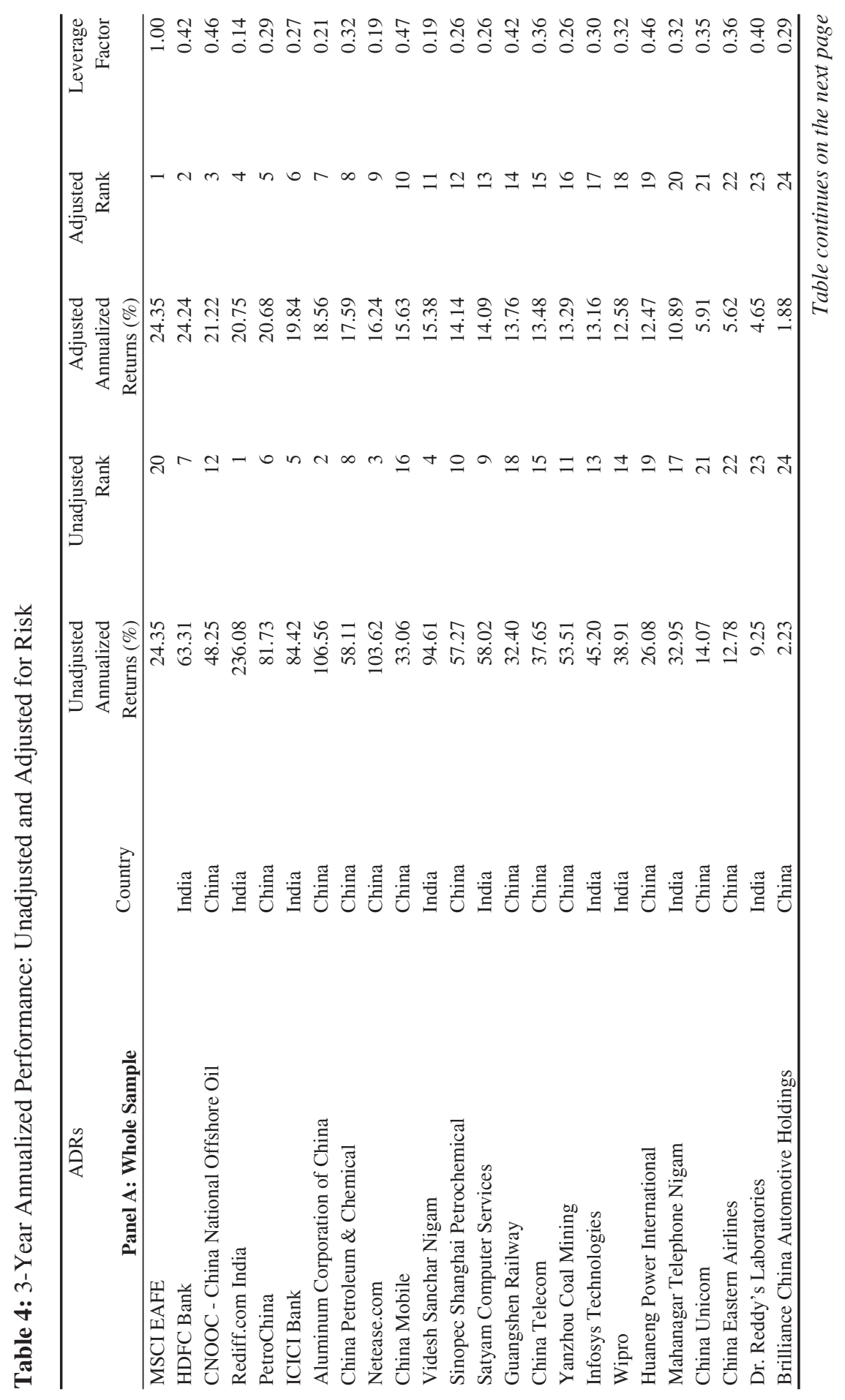



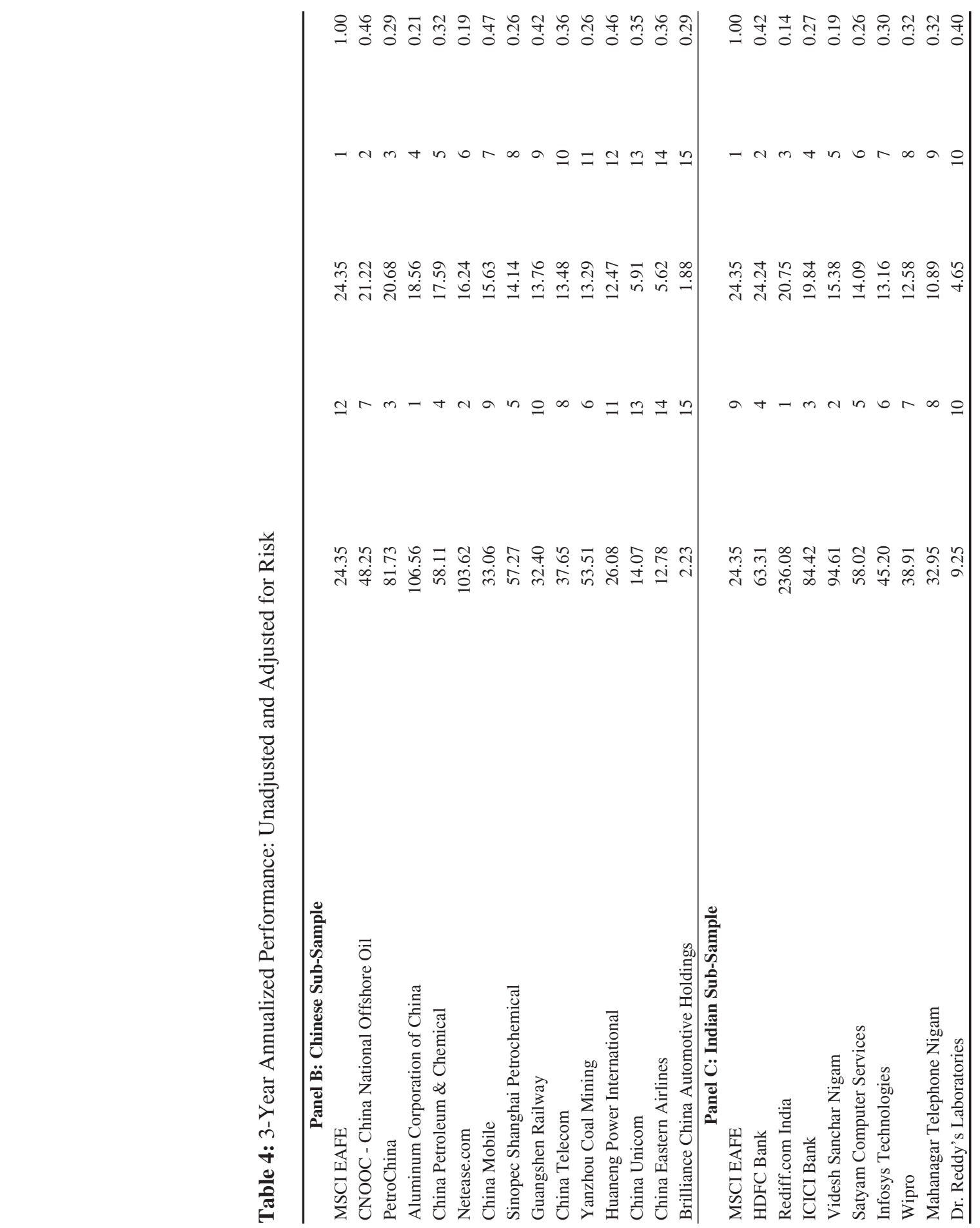
monthly basis or 21.13 percent (slightly off the 21.22 percent in Table 4 due to rounding) on an annual basis. Note that the monthly risk of the portfolio is 0.46 $\mathrm{x} 7.62=3.51$ percent, which is the same as the monthly standard deviation of the benchmark MSCI EAFE Index. This investment strategy, therefore, enables the investor to earn superior returns for an average level of risk. It may be noted that the above example assumes that the returns on risk-free US treasury bills are not correlated with the returns on the ADR.

\section{Conclusion}

ADRs represent a convenient vehicle to access emerging markets such as China and India for international investors who are contemplating global portfolio selection. These securities are structured to serve the needs of both investors and issuers. There are 161 ADRs from the China-India region that are listed on U.S. markets and they provide a menu of investment opportunity across diverse industry groups. This study examines the nature of these ADRs in order to identify the depositary bank, sponsorship status, industry classification, and market listing.

Prior research has examined the performance of individual Chinese and Indian stocks in local currencies. However, risk-adjusted returns reported in terms of US dollars are more useful to international investors for security selection and portfolio construction. In addition, from the global investor's point of view, the instrument of choice for accessing Chinese and Indian stock markets is the ADR, not the underlying stock itself. Hence, there is need for rigorous evaluation of the performance of these ADRs using metrics grounded in modern portfolio theory. This study contributes to academic and practitioner literature by meeting this need.

In order to facilitate comparison with international stock market performance, this study uses the Morgan Stanley Capital International EAFE Index to evaluate the risk-adjusted returns of Chinese and Indian ADRs. Some of these ADRs have unadjusted returns which are high, but once risk is factored in, the adjusted returns are less attractive. On the other hand, some ADRs with modest returns may be quite attractive to international investors, when their returns are adjusted upward for low risk. Global investors may want to examine each of these securities in detail, in order to evaluate them further for possible inclusion in an investment portfolio. Of course, the contribution of a security to portfolio return and risk should matter more to the global investor than the return and risk of an individual security.

This study provides empirical evidence on the risk and return characteristics of ADRs from China and India. It would be beneficial to update this information on a continuing basis, in order to provide ongoing documentation to international investors who seek to diversify into these markets. Future research could focus on decoupling the return to these ADRs into its constituent components: riskadjusted return in the domestic currency and fluctuation in the exchange rate. 
Author statement: The submitting author is Ajay Samant, National City Endowed Chair in Finance, Western Michigan University, Kalamazu, Michigan, USA. E-mail: ajay.samant@wmich.edu. Onur Arugaslan is an Associate Professor at the same University.

\section{References}

Aggarwal, R., Dahiya, S., and Klapper, L. F. (2005). American Depositary Receipts $(A D R)$ Holdings of U.S. based emerging market funds. World Bank Policy Research (Working Paper No. 3538).

Alexander, G. J., Cheol S. E., and Janakiramanan S. (1987). Asset pricing and dual listing on foreign capital markets: A note. Journal of Finance, 42, 151-158.

Alexander, G. J., Cheol, S. E., and Janakiramanan S. (1988). International listings and stock returns: Some empirical evidence. Journal of Financial and Quantitative Analysis, 23, 135-151.

Chang, E. C., and Lewellen, W. G. (1984). Market timing and mutual fund investment performance. Journal of Business, 57(1), 57-72.

Eichler, S., and Maltritz, D. (2008). Currency crisis prediction using ADR market data - An options-based approach. EFA 2008 Athens Meetings Paper.

Henrikkson, R.D., and Merton, R.C. (1981). On market timing and investment performance II: Statistical procedures for evaluating forecasting skills. Journal of Business, 54(4), 513-533.

Jaiswal-Dale, Ameeta and Jithendranathan, Thadavillil, (2001). Fluctuating returns of dual listings: Domestic and ADR markets. EFMA 2001 Lugano Meetings Paper.

Jayaraman, N., Shastri K., and Tandon K., (1993). The impact of international cross-listings on risk and return: The evidence from American Depositary Receipts. Journal of Banking and Finance, 17(1), 91-103.

Jensen, M.C. (1968). The performance of mutual funds in the period 1945-64. Journal of Finance, 23(2), 389-416.

Kon, S. J., and Jen, F. C. (1979). The investment performance of mutual funds: An empirical investigation of timing, selectivity, and market efficiency. Journal of Business, 52(2), 263-289.

Modigliani, F., and Modigliani, L. (1997). Risk-adjusted performance. Journal of Portfolio Management, 23(2), 45-54.

Officer, D., and J. Ronald H. (1987). ADRs: A substitute for the real thing? Journal of Portfolio Management, 61-65.

Pedersen, C.S., and Satchell, S.E., (2002). On the foundation of performance measures under asymmetric returns. Quantitative Finance, 2(3), 217-223.

Umutlu, Mehmet, Salih, Aslihan A., and Akdeniz, L. (2007). Do ADR listings affect the dynamics of volatility in emerging markets? SSRN Working Paper. 
Saudagaran, Shahrokh M. (1988). An investigation of selected factors influencing the decision to list on foreign stock exchanges. Journal of International Business Studies, 101-128.

Sharpe, W. F. (1966). Mutual fund performance. Journal of Business, 39(1), $119-138$.

Solnik, B.H., and McLeavey, D., (2004). International investments (5th ed.). Reading, MA: Addison-Wesley.

Sortino, F. A., and Price, L. N. (1994, Fall). Performance measurement in a downside risk framework. Journal of Investing, 59-65.

Treynor, J.L. (1965). How to rate management of investment funds. Harvard Business Review, 43(1), 63-75. 


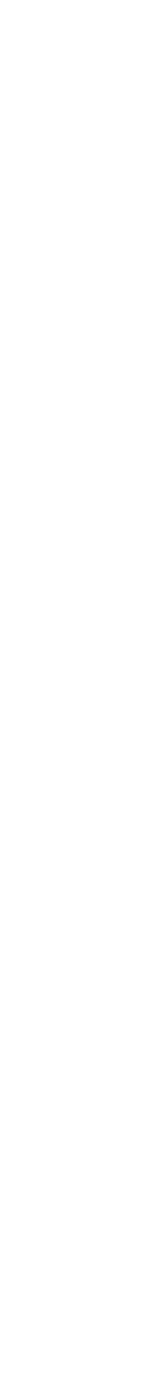

